\title{
МОДЕЛЬ ПСИХОЛОГО-ПЕДАГОГИЧЕСКОГО СОПРОВОЖДЕНИЯ МЕЖЛИЧНОСТНЫХ ОТНОШЕНИЙ СТУДЕНТОВ С ИНВАЛИДНОСТЬЮ В ОБРАЗОВАТЕЛЬНОЙ СРЕДЕ ВУЗА
}

\section{MODEL OF PSYCHOLOGICAL \\ AND PEDAGOGICAL SUPPORT \\ OF INTERPERSONAL RELATIONSHIPS \\ OF STUDENTS WITH DISABILITIES \\ IN THE EDUCATIONAL ENVIRONMENT \\ OF THE UNIVERSITY}

\section{O. Polenova \\ S. Leshchenko \\ N. Peshkova}

Summary: The article reveals the relevance of studying psychological and pedagogical support of interpersonal relationships of students with disabilities in the educational environment of the University. The features of interpersonal relations development in students of this category are considered. The model of psychological and pedagogical support is described in detail, as well as an assessment of the productivity of its implementation. This article will be of interest to specialists working with students with disabilities.

Keywords: model of psychological and pedagogical support, interpersonal relationships, students with disabilities, educational environment of the University.

\author{
Поленова Ольга Анатольевна \\ Тульский государственный педагогический университет \\ им. Л.Н. Толстого \\ olechka.polenova.96@mail.ru \\ Лещенко Светлана Геннадьевна \\ К.псх.н., доцент, Тульский государственный \\ педагогический университет им. Л.Н. Толстого, \\ svet-lanal@mail.ru \\ Пешкова Наталья Александровна \\ К.nсх.н., доцент, Тульский государственный \\ педагогический университет им. Л.Н. Толстого, \\ na_peshkova@mail.ru
}

Аннотация: В статье раскрыта актуальность изучения психолого-педагогического сопровождения межличностных отношений студентов с инвалидностью в образовательной среде вуза. Рассмотрены особенности развития межличностных отношений у студентов данной категории. Подробно описана модель психолого-педагогического сопровождения, а также представлена оценка продуктивности ее реализации. Данная статья будет интересна специалистам, работающим со студентами с инвалидностью.

Ключевые слова: модель психолого-педагогического сопровождения, межличностные отношения, студенты с инвалидность, образовательная среда вуза.

изучения данной проблемы на сегодняшний день.

Особенности психолого-педагогического сопровождения студентов с инвалидностью отражены в работах О.И. Купреевой, О.А. Козыревой и др. [6, 5]. Изучением межличностных отношений внутри студенческой группы занимаются такие ученые, как: Е.Л. Данилова, Е.Л. Козуб $[2,4]$. Специфика выстраивания межличностных отношений студентов с инвалидностью раскрыты в работах Д.А. Фатеевой, Т.В. Климовой, М.Л. Скуратовской, Л.М. Кобриной [8].

Несмотря на широкий выбор работ, направленных на изучение психолого-педагогического сопровождения студентов с инвалидностью, исследований, направленных на изучение развития межличностных отношений студентов данной категории в образовательной среде вуза, на сегодня недостаточно.

Исходя из всего вышесказанного, проблема исследования определяется противоречием: с одной сто- 
роны, необходимости психолого-педагогического сопровождения межличностных отношений студентов с инвалидностью для успешного трудоустройства студентов данной категории, с другой стороны, недостаточной разработанности данной проблемы в психолого-педагогической и специальной литературе.

Одной из главных задач сопровождения студентов с инвалидностью является организация конструктивного сотрудничества, которое, в свою очередь, открывает перспективы для личностного развития, а также автоматически запускает процессы социальной адаптации и успешной социализации.

Обязательными направлениями процесса сопровождения студентов с инвалидностью являются [5]: диагностическая работа; коррекционно-развивающая работа; консультативная работа; разработка программы всестороннего сопровождения; выбор формы работы по сопровождению; определение индивидуального образовательного маршрута; отслеживание продуктивности реализации модели сопровождения; разработка адаптированной образовательной программы.

Наше исследование проходило в ФГБОУ ВО «Тульский государственный педагогический университет им. Л.Н. Толстого» на базе факультета психологии. Выборку составили студенты с инвалидностью в возрасте от 18 до 21 года.

\section{Основная часть}

Психолого-педагогическое сопровождение межличностных отношений студентов с инвалидностью в вузе - это целостная комплексная, системно-организованная деятельность, в которой создаются социально-психологические и педагогические условия для успешного развития межличностных отношений со стороны специалистов различного профиля, действующих согласовано.

Цель модели психолого-педагогического сопровождения - создание оптимальных психолого-педагогических условий для развития межличностных отношений студентов с инвалидностью в вузе.

Объект сопровождения - межличностные отношения студентов с инвалидностью в образовательной среде вуза.

Предмет сопровождения - разработка структуры и содержания психолого-педагогического сопровождения межличностных отношений студентов с инвалидностью в образовательной среде вуза.

Участники модели сопровождения: педагог-психолог, куратор учебной группы, родители студента с инвалидностью, одногруппники студента с инвалидностью, студент с инвалидностью.

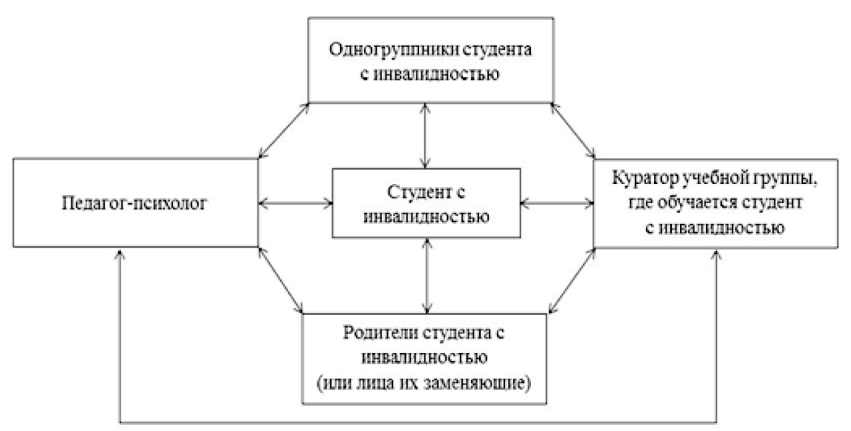

Рис. 1. Схема взаимодействия участников модели психологопедагогического сопровождения межличностных отношений студентов с инвалидностью в образовательной среде вуза

Предлагаемая нами модель психолого-педагогического сопровождения включает в себя несколько этапов:

\section{1. Диагностический этап.}

Цель: диагностика показателей развития межличностных отношений студентов с инвалидностью в образовательной среде вуза.

Задача: составление и реализация диагностической программы, направленной на изучение показателей развития межличностных отношений студентов с инвалидностью в образовательной среде вуза.

\section{2. Организачионный этап.}

Цель: разработка коррекционно-развивающей программы, направленной на развитие межличностных отношений студентов с инвалидностью в образовательной среде вуза.

Задачи:

- пределение направлений, цели и задач коррекционно-развивающей программы;

- проектирование и построение коррекционноразвивающей программы, основанной результатах диагностического этапа;

- написание рекомендаций для кураторов групп, преподавателей, одногруппников студентов с инвалидностью, а так же для родителей студентов с инвалидностью (или лиц их заменяющих);

- распределение обязанностей среди участников психолого-педагогического сопровождения.

\section{3. Формирующий этап.}

Цель: реализация коррекционно-развивающей программы. 
Задачи:

- проведение коррекционно-развивающей работы;

- согласованная работа всех участников психологопедагогического сопровождения.

\section{4. Контрольный этап.}

Цель: диагностика сформированности показателей развития межличностных отношений студентов с инвалидностью в образовательной среде вуза.

Задача: проведение повторного диагностического исследования с применением тех же методик, что и на диагностическом этапе.

\section{5. Аналитический этап.}

Цель: анализ продуктивности проведенной коррекционно-развивающей работы.

Задачи:

- сравнительный анализ полученных данных на диагностическом и контрольном этапе;

- оценка продуктивности проведенной специалистами психолого-педагогического сопровождения работы.

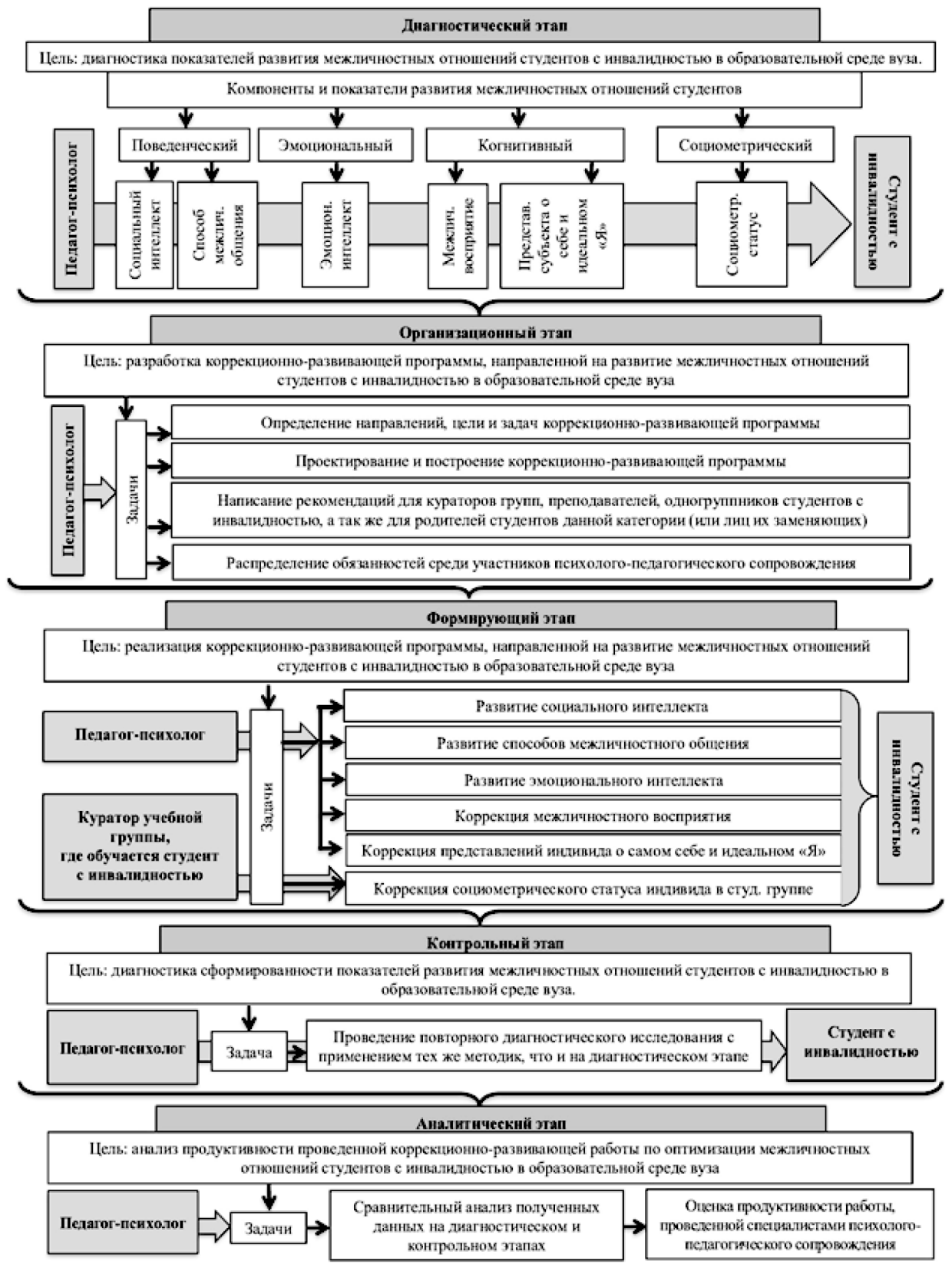

Рис. 2. Схема модели психолого-педагогического сопровождения межличностных отношений студентов с инвалидностью в образовательной среде вуза 
Схема модели психолого-педагогического сопровождения межличностных отношений студентов с инвалидностью в образовательной среде вуза представлена на рисунке 2.

\section{Методы исследования}

Психолого-педагогической литературе понятие «межличностные отношения» определяют как субъективно переживаемые взаимоотношения между людьми, которые проявляются во взаимных влияниях людей друг на друга. (А.А. Бодалев) [1].

На основании проведенного контент-анализа понятия «межличностные отношения», мы выделили компоненты и показатели развития межличностных отношений, которые легли в основу разработки диагностической программы изучения данного феномена у студентов с инвалидностью в вузе:

- Поведенческий компонент. Показатели: социальный интеллект (Тест Дж. Гилфорда «Социальный интеллект»); способ межличностного общения (Тест коммуникативных умений Михельсона (адаптация Ю.З. Гильбуха)).

- Эмоциональный компонент. Показатель: эмоциональный интеллект (Тест на эмоциональный интеллект (Тест EQ) Н. Холла).

- Когнитивный компонент. Показатели: межличностное восприятие (Методика «Исследование восприятия индивидом группы» Е.В. Залюбовской); представление субъекта о себе и идеальном «Я» (Методика «Диагностика межличностных отношений» Т. Лири).

- Социометрический компонент. Показатель: социометрический статус (Методика социометрических измерений Дж. Морено).

\section{Ход эксперимента и его результаты}

Результаты диагностического этапа исследования показали, что межличностные отношения студентов с инвалидностью характеризуются низким уровнем развития социального и эмоционального интеллектов, преобладанием зависимого и компетентного способов общения, в межличностном восприятии у них наблюдается индивидуалистическая и прагматическая направленность, представления о себе и реальном «Я» имеют качественные различия, в студенческой группе преимущественно они имеют социометрический статус «отверженные» или «непринятые». Следовательно, для данной выборки студентов необходимо провести коррекционно-развивающую работу, направленную на развитие всех показателей развития межличностных отношений.

На организационном этапе реализации модели психолого-педагогического сопровождения межличност- ных отношений студентов с инвалидностью в вузе нами бала разработана коррекционно-развивающая программа.

Цель коррекционно-развивающей программы: развитие межличностных отношений студентов с инвалидностью в образовательной среде вуза.

Задачи коррекционно-развивающей программы:

1. Развитие социального интеллекта посредством психогимнастики и анализа конкретных ситуаций;

2. Коррекция способов межличностного общения посредством ролевых игр и групповых дискуссий;

3. Развитие эмоционального интеллекта посредством психогимнастики и рефлекции;

4. Коррекция межличностного восприятия через ролевые и групповые игры;

5. Коррекция представлений индивида о самом себе и идеальном «Я» посредством бесед и аутотренинга.

На занятиях по данной программе мы внедряли следующие методы работы: беседа, групповая дискуссия, парная форма работы, метод игры (психотехника, имитационная и ролевая игры), аутотренинг, рефлексия.

Форма коррекционно-развивающих занятий: групповая.

На формирующем этапе реализации модели психолого-педагогического сопровождения нами бала апробирована коррекционно-развивающая программа, состоящая из 13 занятий, длительность каждого из которых один час. Программа проводилась 1 раз в неделю в специально оборудованном помещении для тренинга.

Параллельно реализации педагогом-психологом коррекционно-развивающей программы, на учебных занятиях куратор группы, где обучается студент с инвалидностью, использует специальные приемы «ситуации успеха» для коррекции социометрического статуса студента с инвалидностью в студенческой группе (это студенты с социометрическим статусом «отвергнутые», «непринятые» и «принятые»). Сюда относятся следующие приемы: «неожиданная радость», «ожидаемая радость», «снятие страха», «коллективная похвала», «авансирование успеха», «персональная исключительность».

После апробации коррекционно-развивающей работы, нами был проведен контрольный этап исследования, на котором осуществлялось повторное диагностическое исследование для оценки продуктивности проделанной работы. С этой целью применялись те же методики, что и на констатирующем этапе.

Изучение социального интеллекта показало, что 
процентное количество испытуемых, имеющих низкий уровень его развития, на контрольном этапе уменьшилось на 70\%. У данных студентов все еще не способны выделять из контекста вербальную и невербальную экспрессию поведения, они плохо понимают отношения. Среднеслабый уровень увеличился на 30\%. У испытуемых способности к познанию поведения ниже среднего. Процентное количество испытуемых имеющих средний уровень развития социального интеллекта увеличилось на 30\%. Студенты легко находят общий язык с окружающими, имеют поддерживать благоприятный психологический климат в группе, проявляют больше интереса, изобретательности и находчивости в работе. Среднесильный уровень увеличился на10\%. Испытуемые выражают интерес к познанию себя, способны выделять экспрессию поведения, легко уживаются в коллективе. Высокий уровень развития социального интеллекта на констатирующем и контрольном этапах имеют 0\% испытуемых.

Изучение способов общения показало, что процентное количество испытуемых, имеющих низкий показатель зависимого способа общения, на контрольном этапе увеличился на 20\%, пониженный - уменьшился на $10 \%$. Средний показатель зависимого способа общения имеют 30\% испытуемых, повышенный - уменьшился до 0\%. Высокий показатель зависимого способа общения на контрольном имеют 0\% испытуемых. Низкий показатель компетентного способа общения уменьшился до 0\%. Процентное количество испытуемых имеющих пониженный показатель компетентного способа общения $20 \%$, средний - увеличился на 10\%. Повышенный показатель компетентного способа общения уменьшился на $30 \%$, а высокий показатель увеличился до 30\%. Агрессивный способ общения у 100\% испытуемых находится на низком показателе.

Изучение эмоционального интеллекта показало, что процентное количество испытуемых имеющих низкий уровень его развития на контрольном этапе уменьшился на $30 \%$, у данных студентов все еще имеются трудности в осознании и понимании своих эмоций, в распознавании эмоций других людей, они плохо управляют своими эмоциями. Процентное количество испытуемых, имеющих средний уровень развития эмоционального интеллекта, увеличился на 10\%, это говорит нам о том, что данные студенты испытывают некие трудности в управлении своими эмоциями, в распознавании и понимании эмоций других людей. Высокий уровень развития эмоционального интеллекта увеличился до 20\%, т.е. испытуемые осознают и понимают свои эмоции, умеют управлять ими и своим поведение.

Изучение межличностного восприятия показало, что процентное количество испытуемых, имеющих индивидуалистическую направленность восприятия группы, на контрольном этапе уменьшилось на 10\%, это говорит нам о том, что для данных студентов группа является средством для достижения индивидуальных целей, они воспринимают группу с точки зрения ее «полезности». Процентное количество испытуемых, имеющих коллективистическую направленность восприятия группы, на контрольном этапе увеличилось до 40\%, т.е. для студентов на первый план выступают проблемы группы или отдельных ее членов, они воспринимают группу как самостоятельную ценность, в совместной деятельности у них проявляется потребность в коллективных, совместных формах работы. Процентное количество испытуемых, имеющих прагматическую направленность восприятия группы, на контрольном этапе уменьшилось на 20\%, для данных студентов группа - это помеха своей деятельности, они уклоняются от коллективных совместных форм деятельности с коллективом.

При изучении представлений субъекта о себе и идеальном «Я» мы рассматривали два основных параметра «Доминирование» и «Дружелюбие». Результатам диагностики показали, что в реальном «Я» по формуле «Доминирование», процентное количество испытуемых, имеющих положительный результат, уменьшилось на 30\%. В идеальном «Я» на диагностическом и контрольном этапах 100\% испытуемых имеют положительный результат по формуле «Доминирование». Это свидетельствует о том, что у них проявляется выраженное стремление к лидерству в общении, к доминированию. Процентное количество испытуемых, имеющих отрицательный результат по формуле «Доминирование», увеличилось на 30\%, т.е. студенты склонны к подчинению, они открыто демонстрируют отказ от ответственности и позиции лидерства. В идеальном «Я» отрицательный результат по формуле «Доминирование» имеют 0\% испытуемых. По формуле «Дружелюбие» в реальном «Я» процентное количество испытуемых, имеющих отрицательный результат, уменьшилось на 40\%, а в идеальном «Я» - на $10 \%$ испытуемых. Это говорит нам о том, что студенты демонстрируют агрессивную и конкурентную позицию, которая мешает успешному сотрудничеству и совместной деятельности в группе. Положительный результат по формуле «Дружелюбие» в реальном «Я» увеличился на 40\%, а в идеальном «Я» - на 10\%, т.е. студенты стремятся к установлению дружелюбных отношений и сотрудничеству с окружающими.

По результатам изучения социометрического статуса, было выявлено, что социометрический статус «звезды» не получил ни один из испытуемых. В числе «предпочитаемых» в своей группе оказалось 20\% испытуемых. Социометрический статус «принятые» в своей группе получили 40\% испытуемых. В числе «непринятых» в своей группе оказалось 20\% испытуемых. Социометрический статус «отвергнутые» в своей группе получили 20\% испытуемых. 
На аналитическом этапе для статистического анализа полученных данных нами был выбран t-критерий Стьюдента [3], результаты которого показали, что полученные эмпирические значения $\mathrm{t}_{\text {эмп }}$ во всех расчетах по всем методикам оказались больше имеющегося $t_{\text {крит }}$ что указывает на нахождение полученных результатов в зоне значимости.

\begin{abstract}
Зак^ючение
Таким образом, по итогу проведенного статистического анализа, мы можем сделать вывод о том, что разработанная нами модель психолого-педагогического сопровождения межличностных отношений студентов с инвалидность в образовательной среде вуза показала свою продуктивность.
\end{abstract}

\section{ЛИТЕРАТУРА}

1. Бодалев А.А. Личность и общение. М.: Международная педагогическая академия, 1995. 328 с.

2. Данилова Е.Л. Особенности межличностных отношений в студенческой группе [Текст] // Актуальные вопросы современной психологии: материалы II Междунар. науч. конф. (г. Челябинск, февраль 2013 г.). Челябинск: Два комсомольца, 2013. С. 70-72. URL https://moluch.ru/conf/psy/archive/81/3474/ (дата обращения 06.01.2019)

3. Ермолаева 0.Ю. Математическая статистика для психологов. 4-е издание испр. М.: Московский психолого-социальный институт: Флинта [Электронный pecypc]. 2006. URL: https://www.psychol-ok.ru/statistics/student/. (Дата обращения: 06.05.2020)

4. Козуб Е.Л. Особенности взаимосвязи общения и межличностных отношений в студенческих группах педагогического вуза: дис. к.пс.н.: 19.00.07. Москва, 1994. 183 c.

5. Козырева 0.А. Организация комплексного сопровождения студентов инвалидов и студентов с ограниченными возможностями здоровья в процессе обучения в вузе [Электронный ресурc] // URL: https://elibrary.ru/item.asp?id=27266505 (дата обращения 08.06.2019)

6. Купреева 0.И. Особенности психологического сопровождения студентов с ограниченными возможностями здоровья. М: МПГУ, 2011. С. $210-211$

7. Фатеева Д.А., Климова Т.В., Скуратовская М.Л., Кобрина Л.М. КиберЛенинка: (2018). Межличностное взаимодействие в условиях инклюзивного образования студентов с ограниченными возможностями здоровья. Российский психологический журнал, 14(3), С. 13-29. [Электронный ресурс] // URL: https:// cyberleninka.ru/article/n/mezhlichnostnoe-vzaimodeystvie-v-usloviyah-inklyuzivnogo-obrazovaniya-studentov-s-ogranichennymi-vozmozhnostyami-zdorovya (дата обращения 10.10.2019)

( Поленова Ольга Анатольевна (olechka.polenova.96@mail.ru ), Лещенко Светлана Геннадьевна (vet-lanal@mail.ru ),

Пешкова Наталья Александровна (na_peshkova@mail.ru).

Журнал «Современная наука: актуальные проблемы теории и практики»

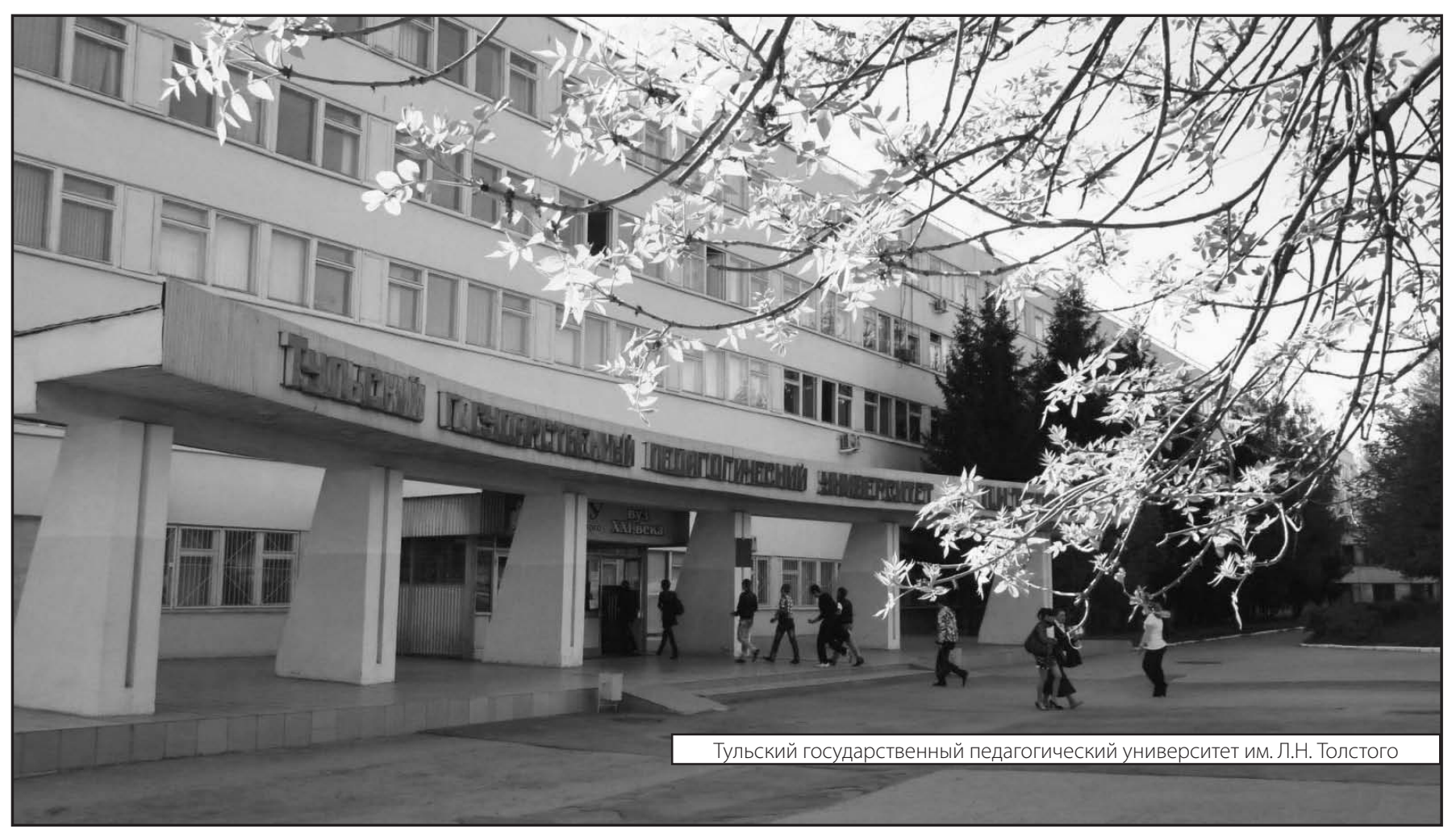

